\title{
An exploration of ramp-up strategies in the area of mass customisation
}

\section{Michael Slamanig* and Herwig Winkler}

Department of Production Management and Business Logistics, Alpen-Adria-Universitaet Klagenfurt, Universitaetsstr, 65-67, 9020 Klagenfurt, Austria

Fax: +43-(0)-463-2700-4097

E-mail: michael.slamanig@uni-klu.ac.at

E-mail: herwig.winkler@aau.at

*Corresponding author

\begin{abstract}
Most approaches in the field of mass customisation have assumed both a given and a stable product range which is continuously improved, e.g., by gradually adding new variants due to shifts in customer preferences. Curiously, within the field of mass customisation there are no studies that address problems related to new product introduction. Although mass customisation is a hybrid competitive strategy that aims at simultaneously achieving cost and differentiation advantage, we found out that a simultaneous ramp-up strategy for new products and product generations is not always practicable for companies in different industrial sectors, such as automotive and electronic industry. Thus, for a successful product introduction in the area of mass customisation we developed two sequential ramp-up strategies: the high-volume-low-mix (HVLM) strategy and the low-volume-high-mix (LVHM) strategy. Results from an explorative study in different industries produced evidence that our ramp-up strategies present two practicable strategic alternatives for successfully introducing new products in the area of mass customisation. To decide which ramp-up strategy should be used, we define a set of ramp-up specific criteria that are presented in this paper. Subsequently, we discuss some selected recommendations for the implementation of the two ramp-up strategies.
\end{abstract}

Keywords: mass customisation; product introduction; ramp-up; ramp-up strategies.

Reference to this paper should be made as follows: Slamanig, M. and Winkler, H. (2011) 'An exploration of ramp-up strategies in the area of mass customisation', Int. J. Mass Customisation, Vol. 4, Nos. 1/2, pp.22-43.

Biographical notes: Michael Slamanig was a Research Assistant at the Department of Production Management and Business Logistics at the Alpen-Adria-Universitaet Klagenfurt. He holds Master's and $\mathrm{PhD}$ in Social and Economic Sciences. His main research interests are hybrid-competitive-strategies, mass customisation, ramp-up management, supply chain management and production networks. He now works for Accenture in their supply chain management practice focused on product innovation and product lifecycle management.

Herwig Winkler is the Head of the Department of Production Management and Business Logistics at the Alpen-Adria-Universitaet Klagenfurt. He holds Master's and $\mathrm{PhD}$ in Social and Economic Sciences. Before his university career, he worked for several companies in the production, logistics and 
planning department. His main research interests are: strategies for value added management, designing of production systems, innovations in logistics and supply chain management, supply chain planning and -controlling, networks and virtual organisations.

\section{Introduction}

During the past few years, comprehensive theoretical work and empirical studies have produced significant evidence for the argument that both a high level of differentiation and a low cost can be pursued simultaneously within the context of hybrid competitive strategies (Blecker and Abdelkafi, 2006a; Fleck, 1995). Today, within the two major categories of sequential and simultaneous hybrid competitive strategies, mass customisation is the strategy most frequently and intensively discussed (Piller, 1998).

Examples from companies in different industries that have successfully implemented the mass customisation strategy show that a more frequent introduction of new and innovative products is a necessary precondition for maintaining long-term competitiveness (Piller, 2005). This concerns not only the continuous improvement of existing products, but also the introduction of new and innovative product generations. An effective and efficient management of product development and product introduction has become an important factor for the success of mass customisers, as they have to react quickly to shifts in the needs of customers (Ogawa and Piller, 2006). The concept of mass customisation itself calls for continuous product and process improvement in order both to increase differentiation permanently and to optimise the fulfilment of customer needs (Piller, 2001). The introduction of new product generations, however, has not yet been taken into consideration. Most previous studies have assumed that the specific product concept is predefined and continuously improved but that it does not involve a radical innovation (e.g., Pine, 1999).

Utterback (2003) refers to the problem when he writes, “... ideas such as lean manufacturing... and mass customization... may be thought of as ways to build core competence and achieve success in differentiating well-known products. These concepts, too, might lead to a dead end when radical change is in the wind." This leads to the question of what happens to mass customisers when the need for a radical product change emerges.

In the case of mass customisation, this means that a company has to attain stable and efficient production of new and highly differentiated products. In order to reach this target, product introduction has to be carried out expeditiously, cost-efficiently, and with a high level of quality. Therefore, the question is how to achieve this target without losing the hybrid competitive position. Within the process of product introduction, the ramp-up phase poses extraordinary challenges. During this short period, the new product has to be transferred from product development to stable production in high volumes and varieties (Terwiesch and $\mathrm{Xu}, 2004)$. Although the problem of ramp-up management has been increasingly discussed within academic society and business world for more than ten years, until now there is no widely accepted definition and delimitation of the term ramp-up (Kuhn et al., 2002). In general, ramp-up marks the period between the end of 
product development and full capacity production (Wiesinger and Housein, 2002). To concretise this broad definition of the term, we define ramp-up as the period between the release of pilot production and the achievement of stable production in terms of attaining the designated quality and output targets. In order to reach these targets, an adequate management has to ensure that the ramp-up is effectively and efficiently planned, organised, carried out and controlled as well as monitored (Schuh et al., 2005). Therefore, ramp-up management has to be supported by specific strategies, instruments and methods. Either insufficient preparation or inefficient execution of the ramp-up significantly affects the success of a new product. Manufacturing systems and processes of industrial companies are, as we found out in our research, mostly and directly affected by ramp-up activities. Figure 1 provides a generic overview about the single phases, processes and milestones of an exemplary product development project.

Figure 1 The ramp-up phase within the early lifecycle stages of a new product

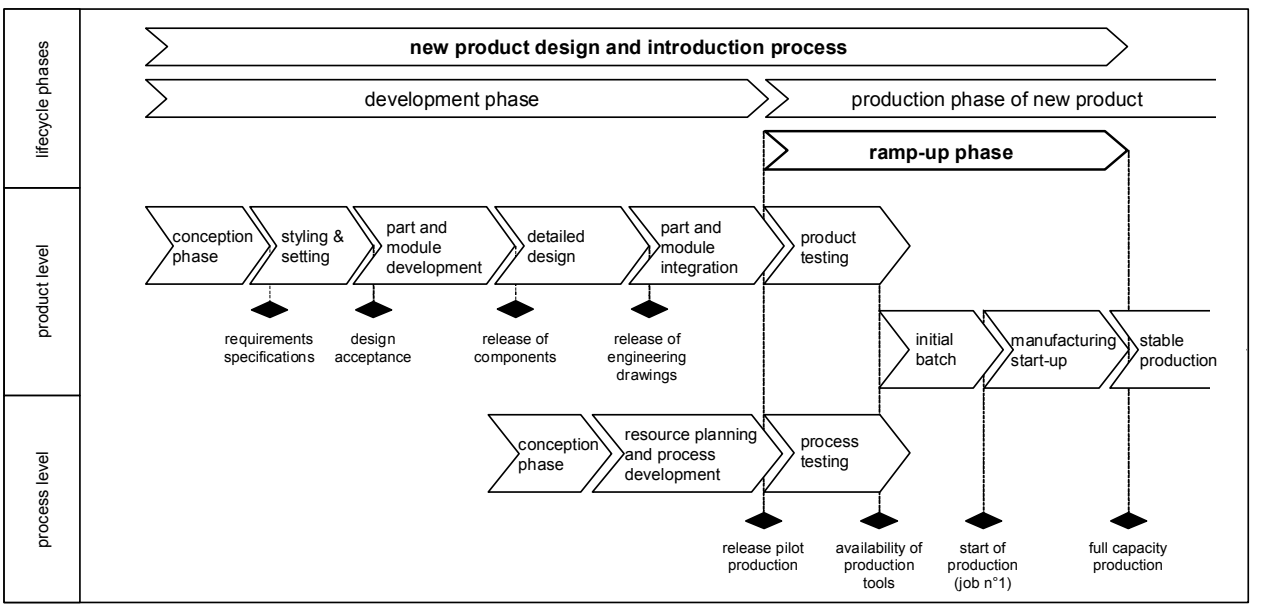

Additional costs, quality problems, and defaults in delivery all result in lost sales, yield losses, and even overdue amortisation (Pelousek and Bauer, 2005). Although the quality of the ramp-up largely depends on product and process maturity at the start of production, which are in turn mostly determined by product development, adequate ramp-up strategies contribute substantially to a successful product introduction (Schuh et al., 2005). A systematic and selective approach within the ramp-up can help a company overcome its difficulties and maintain its strategic position as a mass customiser. The definition of ramp-up strategies is part of the ramp-up management and should take place during the product and process development stage. Although a ramp-up strategy has to integrate various aspects of different business functions, such as marketing, sales, procurement, research and development, production and logistics, in this contribution we will mainly focus on issues related to the field of production management. Manufacturing systems and processes of industrial companies are, as we found out in our research, mostly and directly affected by ramp-up activities.

In order to overcome the ramp-up-specific problems within the product introduction, we have developed two different ramp-up strategies: the high-volume-low-mix (HVLM) strategy and the low-volume-high-mix (LVHM) strategy (Winkler et al., 2007a). The choice for the right ramp-up strategy is determined by the situation under which the 
product introduction is conducted. Therefore, we have defined a set of specific criteria that supports this strategic decision (Winkler et al., 2007a). In this paper we will show which of the two strategies is to be preferred for each specific situation. Results from an explorative study which we carried out in different industries are presented to demonstrate the practicability of our two strategies. In the last section, we will both demonstrate how to implement the two strategies successfully and discuss the results of our work.

\section{Basics of mass customisation and requirements for new product introduction}

\subsection{General principles of mass customisation}

With the determination of a competitive strategy, a company decides how to align, externally and internally, a specific strategic business unit (SBU). On the one hand, the company defines how it can create an external competitive advantage, which essentially means how it can differentiate itself from its competitors. On the other hand, a competitive strategy influences the content of functional strategies (Fleck, 1995; Blecker and Kaluza, 2004). Functional strategies, such as production and logistics strategies, specify how to use the company's resources efficiently in various functional areas in order to obtain competitive advantages (Blecker and Kaluza, 2004; Winkler, 2006).

In reference to two possible kinds of competitive advantages, a high level of differentiation on the one hand and low cost on the other, Porter developed the concept of generic competitive strategies during the 1980s. Porter assumes that the strategies of differentiation and cost leadership contradict one another. Therefore, a company has to decide on one type of strategy in order not to become stuck in the middle. Over the past few decades, Porter's strategies of competition, cost leadership, differentiation and focus have become widely accepted in both the academic and business worlds.

Due to extensive changes within the patterns of both the supply and demand sides in recent years, it is almost universally agreed that Porter's generic competitive strategies seem to be increasingly insufficient in many industries today. Pursuing a competitive strategy that aims only at one strategic position, either the cost or the revenue side, may no longer suffice to confer a major advantage (Kotha, 1995; Blecker and Abdelkafi, 2006a). Companies are increasingly forced both to expand continuously and to customise their portfolio of products and services in order to react more quickly to the growing individualisation of demand. At the same time, costs have to be continually reduced in order to achieve success and profitability in times of increasing global competition. Therefore, the need for new and adequate competitive strategies has emerged. Strategies are needed that either abolish or quasi-synthesise Porter's alternative hypothesis, thereby enabling companies to produce goods at low cost at the same time as they also produce them with a high degree of differentiation. By now, comprehensive theoretical work (e.g., Hill, 1988) and empirical studies (e.g., Miller and Dess, 1993) have produced evidence that a competitive strategy does not necessarily imply choosing between differentiation and cost leadership. Rather, both strategic positions can be pursued simultaneously within the context of a hybrid competitive strategy. 
Although mass customisation has been discussed for more than a decade in the literature, the practical implementation of this strategy was limited for a long time by trade-offs between constitutive targets, such as production costs and variety. Today, new manufacturing and information technologies seem to offer the necessary capabilities to weaken or even abolish the existing trade-offs (Proff and Proff, 1997; Blecker and Abdelkafi, 2006a; Asperen et al., 2008). Examples from the business world show that new production and information technologies have made essential contributions to implementing and successfully pursuing the strategy of mass customisation (e.g., Piller and Stotko, 2002; Blecker et al., 2005; Blecker and Abdelkafi, 2007).

In the economic and technical literature, several types of mass customisation are distinguished (Piller, 2001). The continuum ranges from high volume batch production to pure customisation and involves different levels of customer integration and manufacturing complexity. A number of criteria, such as the type and complexity of the product, the decoupling point or the specific differentiation attributes, determine the type of mass customisation (Blecker and Abdelkafi, 2006b, 2006c). In our study, we have focused on mass customisers that produce standardised products which are customisable by the customers. This means that customers have the opportunity to configure the products themselves by choosing from a range of several given variants.

\subsection{Importance of new product introduction within the strategy of mass customisation}

Two major facets of mass customisation have been disregarded till now: first, the long-term development of SBUs; second, the fact that even the best and most profitable products become obsolete over time. The concept of mass customisation itself calls for a continuous improvement of existing products and processes by simultaneously reducing cost and increasing differentiation (Pine, 1999). The necessity of following such an incremental innovation strategy is undisputable, as it helps the company both to fulfil customer requirements better and to adjust to customer needs over time. By systematically managing product variety new variants of product components can be included in the customisation package through the collection and analysis of configuration and sales data. Simultaneously, costs are kept at a low level because of continuous process improvements throughout the entire supply chain within process management. Process improvements concern e.g., more efficient planning and forecasting, sourcing and procurement processes, assembly processes and/or distribution services. These small innovation steps do not extensively change the existing product concept and process structure but all contribute to an extension of the product life cycle and the middle-term maintenance of competitive advantages. These activities, however, do not negate the need for radical product change in the long run. Some products reach the limit of their improvement possibilities, as when product improvements are no longer valued by customers after a certain stage in the product life cycle or new technological standards for products are established. On the other hand, the process technologies applied to produce and deliver products reach their limits when they do not offer any additional improvement possibilities and cost reduction potentials. At this point competitive advantages are endangered if the company does not act. Radical product changes take place discontinuously and usually call for extensive changes in the existing product concepts, their interrelated parts, modules and/or systems as well as their associated production and logistics processes (Henderson and Clark, 1990). Product 
concept by definition is the scheme under which the functions of a product are allocated to physical components, whereas functional structures can be created at different levels of abstraction, such as parts, modules and systems (Ulrich, 1995). The need for process renewal in the context of radical product change mostly occurs due to technological innovation. However, also the upstream and downstream business processes underlie changes in the case of product change as they are adapted to the needs of the new product. Thus, mass customisation should not longer be regarded as a static approach of continuously improving the product concept and its related process structures, but rather include the need for discontinuous, radical change. Figure 2 extends the range of tasks in the traditional view of mass customisation by including the discontinuous introduction of new and innovative product generations.

Figure 2 Extending the traditional view of mass customisation by new product introduction

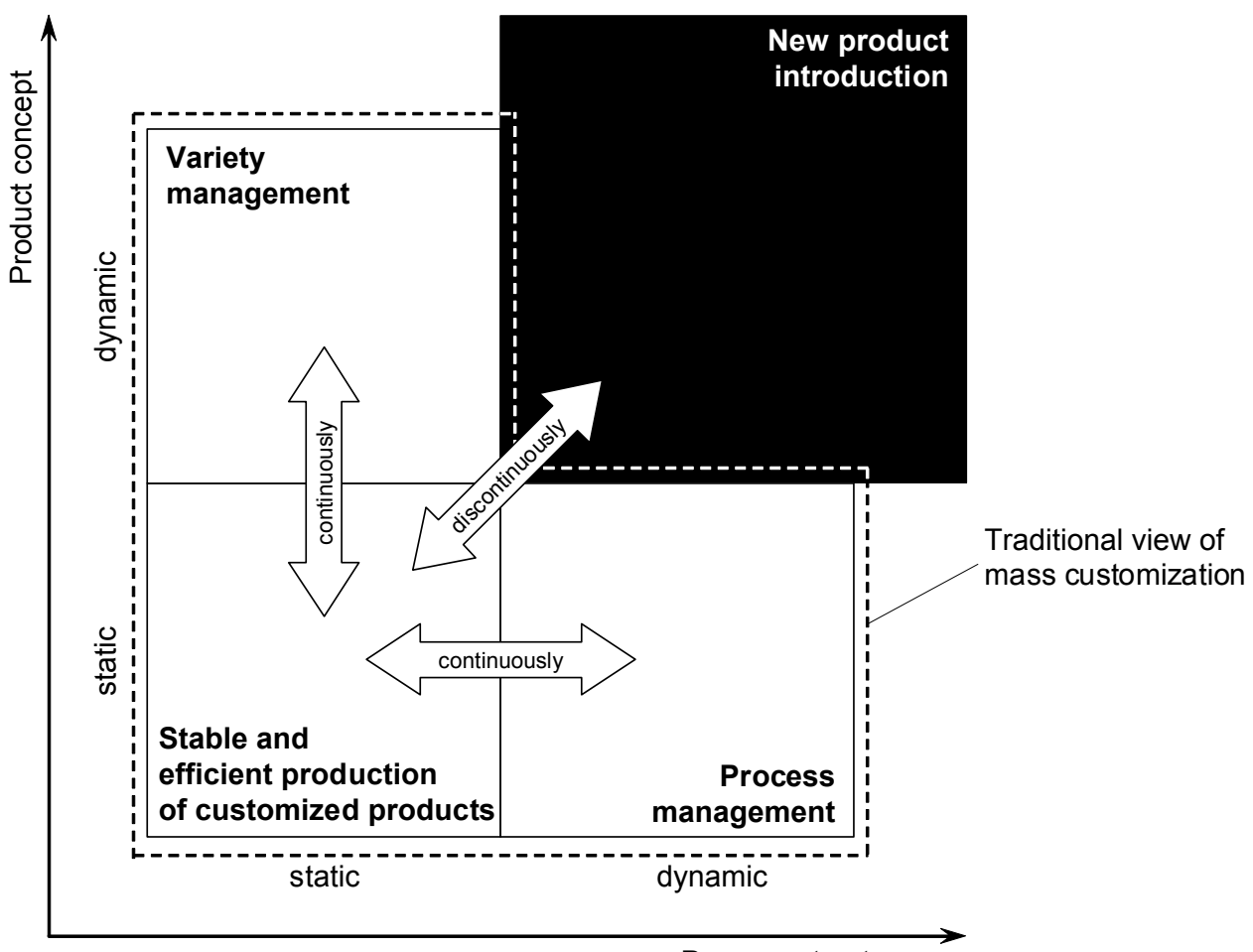

Process structure

The introduction of a new product is always associated with a strategic decision in the context of strategic planning. Before a product change is executed, the company has to define a ramp-up strategy that supports the company's efforts to achieve its designated strategic objectives. In this article, we assume that a company that successfully pursues the strategy of mass customisation aims at maintaining the same strategic position in the same SBU after the product change is accomplished. This means that after the product change, at least two of the previously attained competitive advantages have to be maintained in order for the company not to lose its competitive position. 
The choice of which ramp-up strategy to use, therefore, cannot be made freely; it is determined rather by the extent of modifications to products and processes as well as the specific situation in which the product change is conducted. Different conditions, such as the specific type of mass customisation as well as the prevailing competitive situation, influence the type of market entrance and therefore determine which ramp-up strategy should be implemented.

Figure 3 Strategic options for realising a product introduction in mass customisation

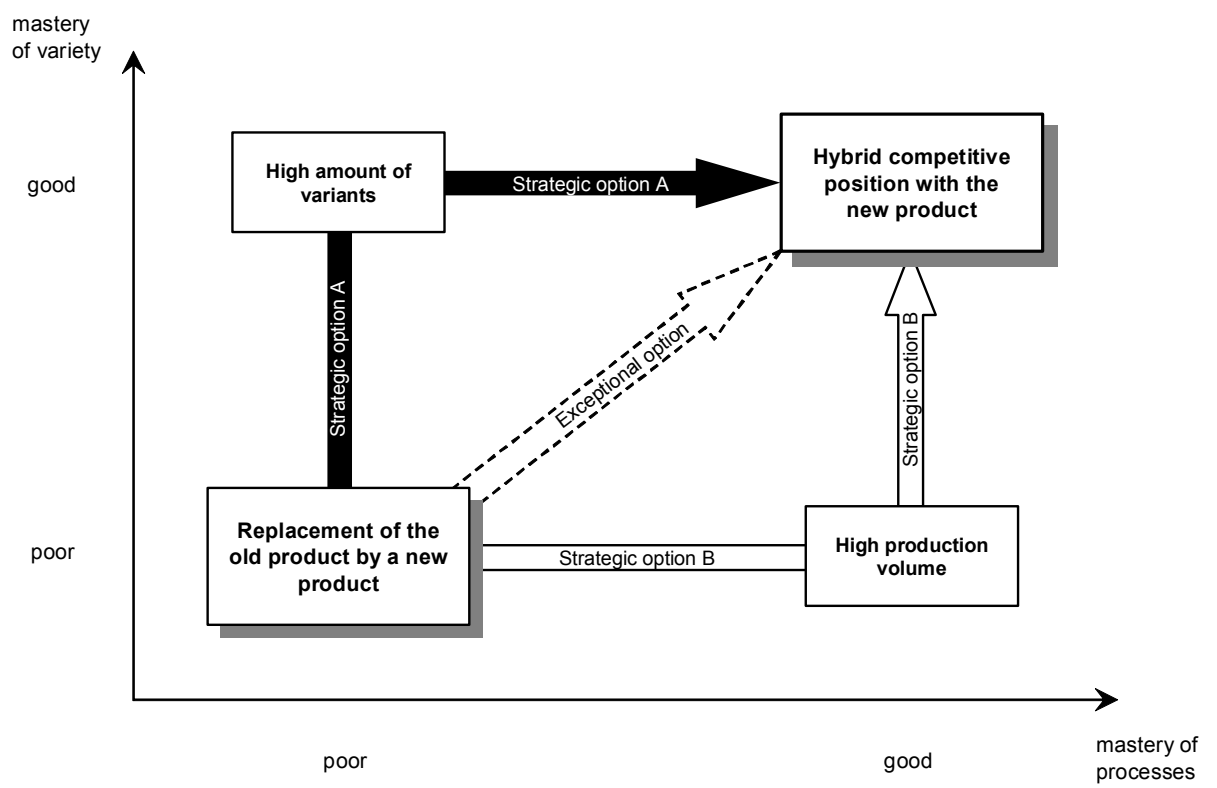

An adequate ramp-up strategy has to enable the company to gradually scale up its production volume, whereas product variants are to the same extent simultaneously increased. At the same time, the production volume of the forerunner product is scaled down in order to minimise overcapacity. This strategy, however, carries a high risk of losing market share and not achieving the intended strategic position. The choice of whether to pursue a sequential or simultaneous ramp-up strategy, in order to reach the intended strategic position, partly depends on the market turbulence and on the competitive situation. A simultaneous ramp-up strategy may work well if competitive pressure is low and time is not a critical factor for success. Under these conditions, a company has time to incrementally improve its products and all links in its value chain in order to reach the intended competitive position. This most likely occurs if a company launches an innovative product and consequently emerges as an innovator, wherein the product's and process's complexity are at a low to medium level. Product complexity can be measured by the number and variants of components of a specific product and the number, type and variability of the interrelations between the single elements (Ulrich and Probst, 1995) that determine the number of configuration possibilities as well as their restrictions. Process complexity is directly related to product complexity and increases with the number and variety of activities needed to procure, manufacture, assemble and deliver products (Abdelkafi, 2008). Both because of intense competition in the highly segmented markets in which mass 
customisers usually operate and time-to-market is absolutely critical to future success, a simultaneous product change strategy is often not applicable and should represent an exceptional option. For that reason, adequate ramp-up strategies have a sequential character and must ensure that the intended competitive position can be achieved expeditiously, cost-efficiently, and with a high level of quality. In contrast to the concept of outpacing strategies (Gilbert and Strebel, 1987), the product change within mass customisation consciously aims at maintaining the fast achievement of the previously attained hybrid competitive position. Figure 3 points out the general strategic options for realising the product change.

\subsection{Ramp-up specific problems during product introduction within the strategy of mass customisation}

For companies pursuing the strategy of mass customisation, the ramp-up of a new product poses extraordinary challenges. Mass customisers are obliged to carry out a ramp-up that meets two specific goals. The first goal is to scale up production to high volumes for obtaining economies of scale. The second goal is to produce and offer an adequate amount of variants in order to fulfil the needs of individual customers. This means that during the ramp-up the company has to attain a stable and efficient production of new and highly differentiated products. In contradistinction to cost-efficient and stable production at high volumes, the ramp-up phase is characterised by a set of specific problems, such as high complexity, high dynamics, uncertainty, high pressure to act, temporal limitations, high levels of interdependence between the processes and a large number of players with different goals and interests (Winkler et al., 2007b). Shortly before the launch of the new product, the complex interaction between people, product, processes, and technology has to be accomplished. A reduction in the degree of vertical integration creates additional complexity, as numerous interwoven processes between the single companies have to be configured and controlled. Under these conditions, companies need to introduce a new product onto the market in a set period, along with the required quantity, quality, and variety, all while staying on budget (Winkler and Slamanig, 2008). Insufficient preparation or inefficient execution of the ramp-up will significantly affect the success of a new product. Mismanagement often leads to additional costs, quality problems and defaults in delivery which, in turn, result in lost sales, yield losses, and even overdue amortisation.

In comparison to the management of the ramp-up of the new product, the management of the phase-out of the old product plays a minor role. Nevertheless, the phase-out strategy has to be strictly aligned with the particular ramp-up strategy. The same applies to the product development strategy. The phase-out strategy largely depends on the prevailing demand for both the old and new product at the time of the product change and is part of a conscious product policy. It is imaginable that the company will continue producing the old product for a defined period, even though the new one is already being produced and distributed. Continuing to produce the old product may be useful in order to utilise capacity, if there is low demand for the new one at first. A number of different phase-out strategies are reported in the literature (e.g., Clark and Fujimoto, 1991). Due to the product-specific and 
firm-specific criteria influencing the choice of the phase-out strategy, we will not discuss the phase-out problem in the present study.

\section{Development of appropriate ramp-up strategies for product introduction within mass customisation}

In order to develop appropriate ramp-up strategies for mass customisation, as a first step, it is essential to define the specific ramp-up conditions. In the next step, we will define a set of criteria in order to demonstrate which ramp-up strategy is appropriate for the respective situations. Subsequently, we will present two different ramp-up strategies, the HVLM strategy and the LVHM strategy. These two strategies derive from the specification of different criteria that we have found to be important. Each strategy provides an opportunity to overcome the problems associated with the ramp-up during the product introduction in the context of mass customisation. In the present article we assume that the development of the new product generation and all its variants has already been finished and that the required quantity of sales at the time of market entry has been defined.

\subsection{Definition of criteria for mapping out ramp-up strategies}

The right ramp-up strategy cannot be chosen randomly; it is determined by project specific parameters derived from product development and the situation in which the ramp-up is conducted. Based on an evaluating of the related literature and the results of our explorative study we have defined a set of specific criteria which influences the choice of adequate ramp-up strategies. The criteria described below present those parameters that were mentioned most frequently by the decision makers throughout our interviews. This information, in turn, was used to requery relevant decision parameters for ramp-up strategies in our questionnaire.

Independent of which ramp-up strategy is chosen, all strategies have the same goal: the maintenance of the strategic position as a mass customiser at the end of the product introduction. This means producing high volumes for obtaining economies of scale, thereby realising low cost and offering an adequate amount of variants in order to fulfil the needs of individual customers.

A simultaneous ramp-up strategy what we call high-volume-high-mix (HVHM) strategy seems only to be practical within mass customisation if product and process complexity is low. This kind of strategy, however, might not lead to success if a highly innovative and complex product has to be launched. In doing so, the company runs the risks of delays in market entry or product offering, serious quality problems and/or cost overshooting (Wildemann, 2004). This might result in a loss of customers, net revenues and, in the worst case, competitive position.

Therefore, the product type and innovation level of the product and processes significantly impact the choice of ramp-up strategy. The strategy of mass customisation does not imply a specific product type. The only condition, in order to successfully implement mass customisation, is the existence of markets in which products are permanently used and contribute to the identification of the single customer (Eastwood, 1996). Furthermore, mass customisation assumes that the individualisation of the product creates an explicit added value for the customer (Piller and Ihl, 2002). Depending on the 
specific type of mass customisation, the product spectrum ranges from standard products with high variety to individually customised premium products (Pine, 1999). In this study, we focus on mass customisers, addressing both low and high price segments. Furthermore, we differentiate between product and process innovation. Following Zaltman et al. (1984), we define innovation as any idea, practice, or technology perceived to be new to the unit or organisation adopting it, independent of whether any other organisation has made that step before. Similarly, Thompson (1965) states in his classic definition that innovation is the generation, acceptance, and implementation of new ideas, processes, products or services, but innovations vary in their degree of newness to an adopting unit or organisation. The degree of product and process innovation can be measured by comparing the new product and/or the new processes with the previous state. Almost every product innovation, independent of whether the product innovation level is high or low, leads to changes within the underlying processes or even calls for new processes. This leads to the notion that almost every product innovation is associated with a process innovation (Pleschak and Sabisch, 1996). On the other hand, process innovation does not automatically necessitate product innovation. For instance, the same product can be produced with innovative processes based on new manufacturing technologies. In this contribution we will not discuss process innovations that are not triggered by change activities to a specific product.

A high innovation level describes a new product with new technological attributes and their implications. New attributes exist, for example, when new materials and/or new production techniques come into operation, a new product design is being offered, or the new product fulfils additional functions. Technological implications describe the effects of new attributes on the underlying processes, e.g., the need for redesigning the production and logistics processes (Carillo and Franza, 2006). An example of a high product innovation level is the introduction of a new car model in the premium segment, e.g., the new BMW 7 series. In this case, the innovation level of the underlying processes will be high as well. A low innovation level characterises the introduction of a new product with modified technological attributes. Although at this level the product innovation level is comparatively low, process innovation can be medium to high when, for example, new process technology is employed or a large number of new suppliers accrue. An example of this is the facelift of an existing model within the automotive industry or the introduction of a new, high-end personal computer.

Related to the product innovation level the number of carry-over-parts is another relevant criterion for the choice of an adequate ramp-up strategy. Carry-over-parts are components, modules or integrated systems which are transferred unchanged from existing products to new product generations (Proff and Proff, 2008). The idea behind using carry-over-parts is that not every part of a new product generation has to be basically redeveloped every time. Carry-over-parts help to reduce complexity during new product development and introduction, as logistics and production processes for such parts stay unchanged over a specific period of time. Furthermore, the quality level of carry-over-parts stays constant and cost savings appear due to economies of scale. In case of carrying out a product change whilst following the strategy of mass customisation the decision which parts and variants are considered to be transferred unmodified from the prior product is particular triggered by the modifications and innovations in product design, configuration and customisation (Anderson, 1998). 
An additional criterion for the choice of an adequate ramp-up strategy is the competitive situation within the affected SBU. If competition is low and a low number of substitute products exist, time-to-market is not a critical factor for success. In this particular case, the company has more time to overcome the prevailing product and process complexity. This is directly related to the decision for the company of whether to deliver its product to the market as an innovator or as an early or late follower. Furthermore, the level of the demand for the new product has an impact on the date of market entry. If the relative market share of the forerunner product was high and the same demand is expected for the new product, an early market entry is essential in order to skim the market and not lose market share. This indicates that the timing of the entry to market is a critical decision that affects both the market share and the profitability of the new product.

\subsection{Determination of specific ramp-up strategies}

After defining a set of specific criteria to support the choice of an adequate ramp-up strategy for mass customisation, we will design two ramp-up strategies: the HVLM strategy and the LVHM strategy. Both strategies are radical in the sense that both focus on a fast achievement of one of the two target values, either high volume (cost side) or high mix (differentiation side). After achieving the first target value, both strategies provide a switch in order to achieve the second target value in the next step. This indicates that the HVLM as well as the LVHM strategy represent sequential ramp-up strategies. Figure 4 shows which of the two ramp-up strategies should be used, depending on the specification of selected criteria.

Figure 4 Criteria for the determination of the adequate ramp-up strategy

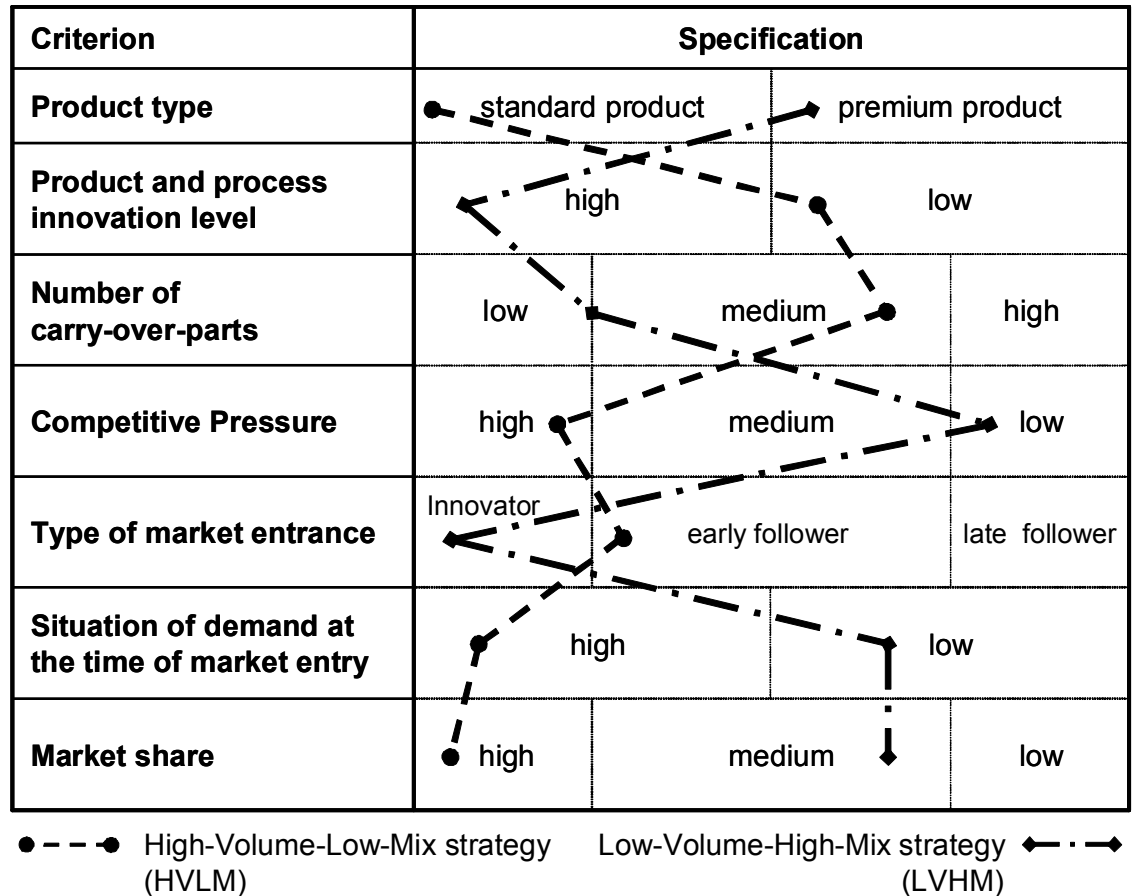


As can be seen from the morphological box, a number of criteria and restrictions are attached to each of the two ramp-up strategies. These market-specific and firm-specific preconditions must be fulfilled in order to implement the specific ramp-up strategy successfully. In the case of the HVLM strategy, the following preconditions are essential.

The HVLM strategy is especially practical for mass customisers producing standard consumer products in high varieties for large markets. Standard consumer products are characterised by a simple structure, where the demand is largely predictable. These products are positioned in the middle price segment. If a new product generation is being introduced into the market, most consumers of these types of products tend to satisfy their needs rapidly. Therefore, they usually do not demand high variety or the opportunity for customisation right from the outset. Furthermore, the number of comparable rival products in the market influences the consumer demand at the time of market entry. In order to not lose market share, the company has to emerge on the market as an innovator or at least as an early follower. Once a new product appears on the market, a number of competitors quickly follow. For this reason, the innovation level of the new product has to be at least low, within the meaning of our classification. It is assumed that, in comparison to standard mass products, consumer loyalty in markets for individualised products is higher, which means customers are willing to wait until the new product is introduced to the market. Additionally, the relative market share of the company within the specific strategic business should be high, in order to ensure that the demand for the new product is high at the time of market entrance. This is essential so that the production quantities can be large, increasing the economy of production costs. An example for the HVLM strategy is the introduction of Volkswagen's (VW) new beetle in the late 1990's. Compared to the old beetle the new model represented a radical innovation as it was completely reengineered and based on a number of new technologies. Volkswagen knew from former experience that introducing a highly innovative car model in short time, with high quality, high variety and in high volumes may endanger the success of the entire project. As VW was aware of the fact that US customers are less demanding variety than for example European customers, they primarily introduced their new beetle in the US market in high volumes with a predefined set of customisable attributes. Additional variants were gradually launched over time. In doing so, VW had enough time left to overcome variety-induced product and process complexity as well as solving quality problems. Whereas high volume production contributed to low production cost. Afterwards, VW introduced their new beetle into the European market with high volume and high variety, resulting in low cost and high differentiation.

For that reason, the HVLM strategy aims for the fast achievement of the required production volume with a predefined number of variants during ramp-up. In doing so, there is a heavy focus both on meeting high demand at the time of market entry and on a rapid realisation of low cost per unit. Besides holding a relative market share, this strategy enables a mass customiser to maintain its strategic position with its primary focus on the cost side. How to achieve a high level of differentiation by pursuing this ramp-up strategy will be outlined later in this paper.

In contrast to the HVLM strategy, the LVHM strategy is practicable for firms offering premium products in high varieties for specialised markets. Premium products are characterised by a complex product structure and are positioned in the high 
price segment. Customers of these products attach great importance to innovation, design, quality, additional features and services. Moreover, such customers want to choose between large numbers of variants in order to configure products that best meet their individual needs. The product innovation level of new premium products has to be high in order to meet customers' expectations and requirements as well as to gain a competitive edge. Therefore, process innovation will be at a high level too. Customers preferring individual premium products demand high variety right from the beginning and are therefore willing to pay a high price premium (Terwiesch et al., 2001). Customer loyalty within the premium segment is even much higher than in the case of individualised standard consumer products. Customers are usually willing to wait until the new product generation is launched. Nevertheless, the risk of losing customers still exists, if the new product is launched too late and/or does not meet the specific consumer's expectations and requirements. This indicates that the demand for premium products is hardly predictable at the time of product introduction. Direct competition in such specialised markets is relatively low, although it still exists. Nonetheless, companies have to play the part of the innovator in order not to lose market share. If customers do not explicitly recognise the added value of the new product, they may drift away to competitors, leading to a decrease in demand. An example for the LVHM strategy is the introduction of BMW's new 7-series. The introduction of the new 7-series was a so called platform project, as it was based on the same power train concept with enhanced performance in terms of efficiency, power density and environmental acceptability. The new model also offered numerous additional customisable interior and exterior attributes. BMW was aware of the fact that for the success of their new model it is essential to offer full product variety and customisation to their customer right from the point of market entry. Consequently, BMW primary introduced their new 7-series into the German market with low volume but high variety in order to overcome product-induced complexity. While mastering product complexity they were able to gradually scale up production outcome and incrementally introduced their new model in other markets, resulting in high differentiation and low production cost respectively.

This indicates that the LVHM strategy aims at introducing the whole product variety, whereas production volume is kept relatively low. In doing so, the LVHM strategy primarily focuses on meeting the expectations and needs of sophisticated customers in premium price segments. Internally, the focus is on handling product complexity. Whereas the demand for high variety is satisfied right from the start, this strategy helps mass customisers maintain their strategic position by concentrating primarily on the differentiation side.

\section{Exploring different ramp-up strategies in selected industries}

\subsection{Objectives of the investigation}

Our overall research objective was to get evidence from empirical data to support our theoretical work on ramp-up strategies in the area of mass customisation. Therefore, an explorative study in different industries in Germany, Austria and Switzerland was carried out between June and September 2008. In our study we mainly focused on 
production ramp-ups of complex mass customised, platform-based consumer products, such as automobiles, bicycles, furniture and notebooks. Given high variety and high competitive pressure, companies in these industries are forced to bring new and innovative products to market and in shorter time spans more frequently. As a result of product and process complexity, companies in such industries cannot meet both of the targets, high variety and high volume, simultaneously during product introduction.

\subsection{Used method}

Our study was based on qualitative and quantitative data collected through a survey in semi-structured interviews, observations and questionnaires in several industries in Germany, Austria and Switzerland between June and September 2008. In our study, we mainly focused on companies that produce platform-based consumer products with high variety, such as automobiles, bicycles, furniture and notebook computers. Given high variety and high competitive pressure, companies in these industries are forced to launch new product generations frequently. To get a better impression for the phenomenon of new product introduction in the area of mass customisation, we first carried out semi-structured interviews with 35 managers of selected companies. The interviews were based on a schedule of open questions that we derived from our main research targets. The aim of the interviews was to get a first insight into the current issues related to new product innovation projects in the field of mass customisation. The interviews were followed up by a questionnaire comprising a set of open and closed questions to explore strategic aspects of new product projects more detailed and gain further insights. From the original set of 40 SBUs, we could collect reliable information on new product introduction projects for 21 SBUs, which constitute the sample for our analysis. Finally, the data collected throughout the interviews and the questionnaires was combined, integrated and verified and comprehensively analysed using descriptive statistics, e.g., frequency, means and standard deviations. The target was to compare the main characteristics of ramp-up strategies in the single mass customisation industries. In this contribution we will solely focus on the results referring to the two types of ramp-up strategies we discussed before: The HVLM strategy and the LVHM strategy.

\subsection{Selected results of the investigation}

The interviews provided an interesting insight into the specific problems related to new product introduction in the area of mass customisation. The experts confirmed our presumption that pursuing the right ramp-up strategy is absolutely critical for the success of new product introduction in the area of mass customisation. As a result of pursuing inadequate ramp-up strategies in the past the many companies suffered from substantial yield losses, which dramatically affected the economic success of new product generations. The results from our survey show that companies in different industries are currently implementing different types of ramp-up strategies. The most frequently mentioned criteria in the questionnaire influencing the choice of which ramp-up strategy should be pursued were almost congruent to our theoretical preconception and the results of our interviews. However, some of the experts pointed 
out that the bundle of activities taking place in their companies during ramp-up projects is not the result of an explicit planning process during product development but rather emerge from adapting activities to the specific internal and external situation in which the ramp-up is executed. The answer to the question which ramp-up strategy the companies pursued in the past, shows significant differences between the four industry samples.

Results from the automotive industry show that within ramp-up projects in the past $75 \%$ of the original equipment manufacturers (OEMs) pursued a HVLM strategy. New product introductions in the automotive industry are usually characterised by a high degree of complexity as well as high product and process innovation rates. Hence, only $25 \%$ of the OEM stated that they launched a new product generation in the past where they ramped up the new product to meet both targets, high production volume and high amount of variants, simultaneously. As the interviews revealed, the HVHM strategy was pursued in a so called 'facelift project' which is characterised by low innovation rate and a high number of components and variants being transferred from the forerunner product generation.

By comparison, results from the bicycle industry illustrate that bike manufactures in the past primary focussed on introducing new product generations in low volume but with a high amount of variants. Only $25 \%$ of the bike manufacturers scaled up production volume and variants simultaneously by following a HVHM strategy.

In the furniture industry, manufacturers pursued the LVHM strategy and the HVHM strategy each with $50 \%$ in the past. None of the furniture manufacturers stated that they scaled-up production to high volume by offering only a limited amount of variants at the point of market entry. The results indicate that the achievement of high variety during new product introduction is a dominant target in the industry for mass customised furniture.

In the notebook industry $60 \%$ of the OEMs pursued a HVHM strategy, whereas only $20 \%$ of the manufacturers followed a HVLM strategy and another $20 \%$ a LVHM strategy. In comparison to the other industries, product innovations in the notebook industry are mainly triggered by suppliers and usually imply low process innovation for the OEM. Therefore, manufacturers of notebooks are able to scale-up new and innovative product generations to high volume and offer a high amount of variants at the point of market entry simultaneously.

To sum up, the empirical evidence derived from the present research allows us to state that our ramp-up strategies offer two appropriate strategic alternatives for the introduction of new and innovative products in the area of mass customisation. By following either the HVLM strategy or the LVHM strategy companies should be able to introduce new and innovative products at low cost and with a high level of differentiation in the medium term during the ramp-up. However, it cannot be neglected that in a limited number of projects, especially in the notebook and furniture industry, in which the innovation level as well as the complexity level of products and processes were relatively low, companies were able to successfully pursue a HVHM strategy to reach low cost and high differentiation in the same time. The following Figure 5 summarises the results of exploring different ramp-up strategies in selected industries and points out that our two ramp-up strategies are frequently pursued in most of the investigated companies, whereas a simultaneous approach often runs the risk of missing the designated targets of new product introduction projects. 
Figure 5 Overall results of exploring different ramp-up strategies in selected industries

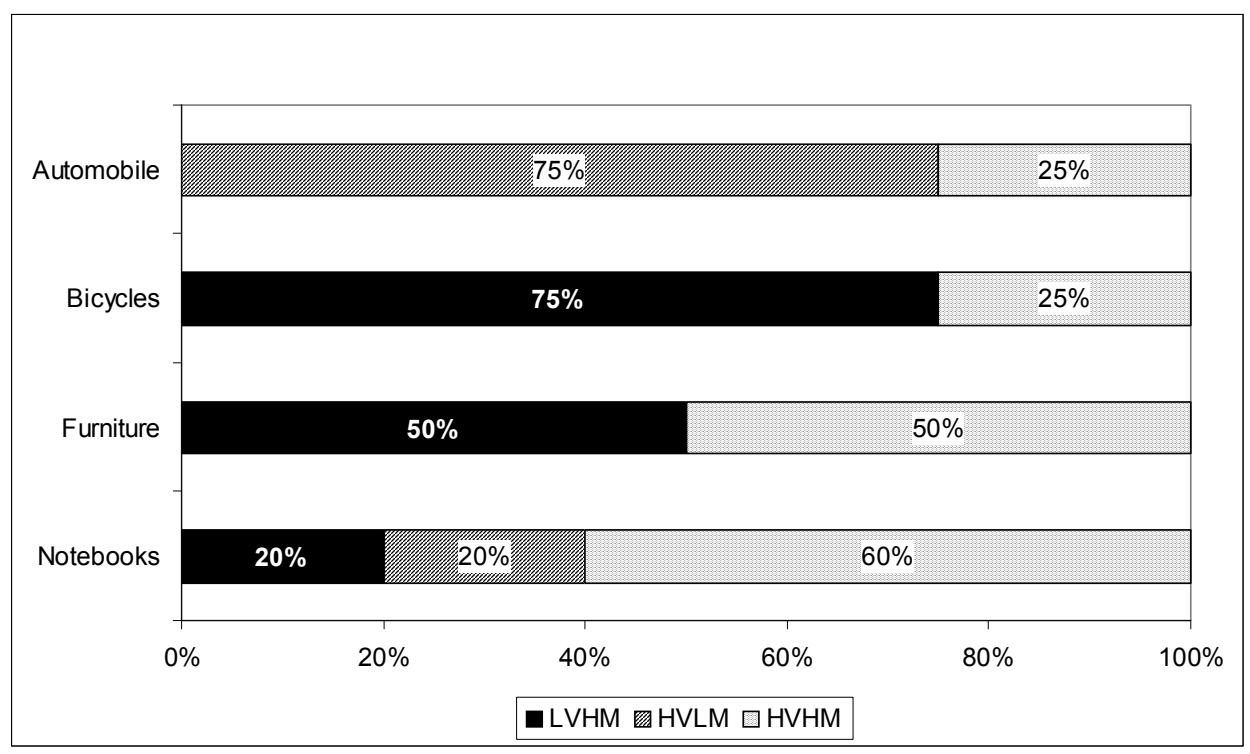

\section{Recommendations for implementing specific ramp-up strategies}

\subsection{Implementation of the HVLM strategy}

The HVLM strategy primarily focuses on the rapid achievement of the required quantities with a predefined number of variants (ramp-up phase A'). This means that not all of the developed variants are produced and offered right from the beginning. Therefore, both the marketing and sales departments have to provide information about expectations concerning the most common and required variants at the time of market entry. The primary target of this ramp-up strategy is early process stability within the production and logistic system by keeping product complexity at a manageable level. Process stability is obtained by an early achievement of learning curve effects (Almgren, 2000). People can concentrate on producing a defined spectrum of variants during early stages of the ramp-up and become used to the processes. In doing so, both economies of scale and economies of quality occur much more quickly, and the costs per unit can be kept low (Piller and Moeslein, 2002). In addition to this, volume-losses and, consequently, losses in net-revenues can be avoided. The company is therefore able to set the market entry price at a lower level. After achieving the required production volume, additional variants are gradually launched until the predefined maximum number of variants is reached (ramp-up phase B'). This means that economies of scope occur as synergies between the different variants that exist. By offering a higher variety, the price can be increased while keeping production costs in line. In doing so, a cost advantage, a differentiation advantage and, therefore, the strategic position of mass customisation can be achieved at the end of ramp-up. 
Implementing the HVLM strategy goes along with both high capacity utilisation and high productivity. This means the production system must be robust in order to cope with high production volumes (Wiendahl et al., 2002). On the other hand, the system must be sufficiently flexible to handle an increasing number of variants (Ahlström and Westbrook, 1999; Qiao et al., 2006; Alvan and Aydin, 2009). Due to the lack of experience with the new product, however, additional capacities might be necessary during the ramp-up period to overcome volume-related problems (Housein et al., 2002).

\subsection{Implementation of the LVHM strategy}

The LVHM strategy aims at rapidly introducing a new product in full variety, while keeping production volume low to medium (ramp-up phase A). Because demand for premium products is relatively low at the time of market-entry, this strategy focuses on product stabilisation at the outset. The main goal is to overcome product complexity within early periods of ramp-up in order to ensure efficient high variety production. This is achieved by the utilisation of economies of scope. In this case, the marketing and sales departments have to provide information about the expected demand for the new product. In order to align production with demand expectations, information about not only the demand at market entry, but also the trend of demand after the product introduction must be provided. Because an increasing demand is assumed, the production volume is continuously increased after product introduction (ramp-up phase B). In doing so, process stability is achieved incrementally during the ramp-up as the production system has to overcome increasing quantities. With the LVHM strategy, the cost per unit is much higher at the beginning because of the prevailing product complexity, but it decreases after an extension of the production volume. Therefore, the market price for the new product is set relatively high right from the outset and stays unchanged over time. If an increase in competition necessitates a price reduction, the company is able to cut prices without yield loss (Milgrom and Roberts, 1990). This is because cost per unit can be reduced by utilising economies of scale and economies of quality over time. Therefore, after focusing on the achievement of high differentiation in the beginning, the LVHM strategy contributes to attaining cost advantages in the second stage of the ramp-up. Consequently, the strategic position of mass customisation can be obtained and maintained by using this ramp-up strategy.

The implementation of the LVHM strategy necessitates a flexible and scaleable production system that is able to handle high variety right from the start and can quickly respond to changes in demand. In contradistinction to the HVLM strategy, overcapacity is not imperative with the LVHM-strategy. This is because of lower production volume in early stages of the ramp-up. Therefore, fewer financial resources are required within the period of ramp-up. Problems may arise, however, due to high variety resulting in higher complexity costs.

Independent of whether the HVLM or the LVHM strategy is pursued, the company has to embark on an incremental innovative strategy after the ramp-up has been completed. This means companies are compelled to continuously reduce their costs after new product introduction. Simultaneously, differentiation has to be permanently strengthened to meet all of the individual customer requirements in the best way possible. Therefore, additional services have to be offered, product quality has to be continually improved, unprofitable product variants have to be eliminated and required variants have 
to be added. An incremental approach contributes to the long-term maintenance of the strategic position of mass customisation until the next product introduction has to be conducted. Figure 6 contrasts both of the ramp-up strategies and thereby illustrates the course of action within each of the two strategies.

Figure 6 The HVLM and LVHM ramp-up strategy for obtaining a hybrid competitive position

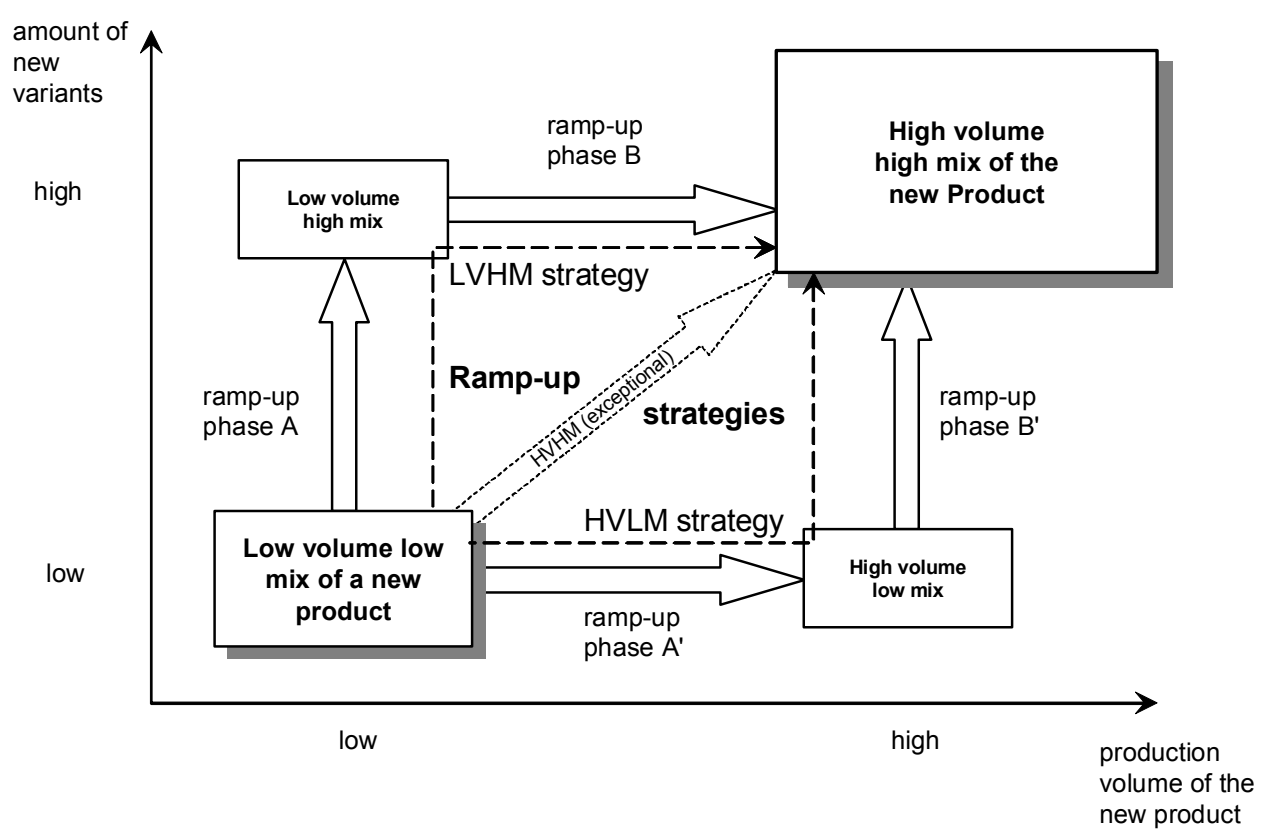

\section{Conclusions}

Today, hybrid competitive strategies such as mass customisation offer new ways for companies to maintain long-term competitiveness. Mass customisation is the most intensively discussed hybrid competitive strategy today. Although many studies of practical examples have shown that mass customisation can be implemented successfully, one major fact has not been taken into consideration thus far: the necessity of eliminating obsolete products and replacing them with new and innovative ones. During the phase of product change the company runs the risk of losing its competitive position as a mass customiser. Unlike companies pursuing the strategy of cost leadership or differentiation, mass customisers are obliged to meet two specific goals within the product change: a stable and cost-efficient production on the one hand and high differentiation on the other. One of the most critical periods within product change is the ramp-up phase. Both insufficient preparation and ineffective realisation of the ramp-up lead to additional costs, quality problems, and/or defaults in delivery. Therefore, the execution of the ramp-up strongly influences the economic success of a new product. We have assumed that 
adequate ramp-up strategies help companies overcome their difficulties and therefore maintain their strategic position as mass customisers in the event of new product introduction. Although mass customisation is a simultaneous hybrid competitive strategy, we have supposed that a simultaneous ramp-up strategy is not practicable for companies pursuing strategies of mass customisation. For this reason, we have presented two sequential ramp-up strategies: the HVLM strategy and the LVHM strategy. In order to decide which of the two ramp-up strategies should be used, we have defined a set of specific criteria. Subsequently, we have outlined the characteristics of these criteria for each of the two strategies in order to show in which specific situations they are most useful. Results from an explorative study in different industries produce evidence that our ramp-up strategies present two practicable strategic alternatives for successfully introducing new products in the area of mass customisation. Future research has to proof the stated findings by quantitative research methods.

\section{References}

Abdelkafi, N. (2008) Variety-Induced Complexity in Mass Customization, Concepts and Management, Erich Schmid Verlag, Berlin.

Ahlström, P. and Westbrook, R. (1999) 'Implications of mass customization for operations management', International Journal of Operations \& Production management, Vol. 19, No. 3, pp. $262-274$

Almgren, H. (2000) 'Pilot production and manufacturing start-up: the case of Volvo S80', International Journal of Production Research, Vol. 38, No. 17, pp.4577-4588.

Alvan, A. and Aydin, A.O. (2009) 'The effects of mass customisation on productivity', International Journal of Mass Customisation, Vol. 3, No. 1, pp.58-81.

Anderson, D.M. (1998) Agile Product Development for Mass Customization, Irwin, Chicago.

Asperen, van E., Pinchetti, T. and Wezel, van M. (2008) 'IT support for mass customisation', International Journal of Mass Customisation, Vol. 2, Nos. 3/4, pp.358-374.

Blecker, Th. and Abdelkafi, N. (2006a) 'Mass customization: state-of-the-art and challenges', in Blecker, Th. and Friedrich, G. (Eds.): Mass Customization: Challenges and Solutions, Springer, New York, pp.1-25.

Blecker, Th. and Abdelkafi, N. (2006b) 'Complexity and variety in mass customization systems: analysis and recommendations', Management Decision, Vol. 44, No. 7, pp.928-929.

Blecker, Th. and Abdelkafi, N. (2006c) 'Modularity and delayed product differentiation in assemble-to-order-systems: analysis and extensions from a complexity perspective', in Blecker, Th. and Friedrich, G. (Eds.): Mass Customization: Challenges and Solutions, Springer, New York, pp.163-186.

Blecker, Th. and Abdelkafi, N. (2007) 'Web-based configuration systems in mass customization: a framework for analysis and case studies', in Blecker, Th., Edwards, K., Friedrich, G., Hvam, L. and Salvador, F. (Eds.): Innovative Processes and Products for Mass Customization, Gito Verlag, Berlin, pp.39-52.

Blecker, Th. and Kaluza, B. (2004) 'Produktionsstrategien - ein vernachlässigtes Forschungsgebiet?', in Braßler, A. and Corsten, H. (Eds.): Entwicklungen im Produktionsmanagement, Verlag Vahlen, München, pp.3-28.

Blecker, Th., Friedrich, G., Kaluza, B., Abdelkafi, N. and Kreutler, G. (2005) Information and Management Systems for Product Customization, Springer, New York. 
Carillo, J.E. and Franza, R.M. (2006) 'Investing in product development and production capabilities: the crucial linkage between time-to-market and ramp-up-time', European Journal of Operational Research, Vol. 171, No. 2, pp.536-556.

Clark, K.B. and Fujimoto, T. (1991) Product Development Performance: Strategy, Organization and Management in the World Auto Industry, Harvard Business School Press, Boston, Massachusetts.

Eastwood, M.A. (1996) 'Implementing mass customization', Computers in Industry, Vol. 30, No. 3, pp.171-174.

Fleck, A. (1995) Hybride Wettbewerbsstrategien: zur Synthese von Kosten- und Differenzierungsvorteilen, Deutscher Universitäts-Verlag, Wiesbaden.

Gilbert, X. and Strebel, P. (1987) 'Strategies to outpace the competition', The Journal of Business Strategy, Vol. 9, No. 1, pp.28-36.

Henderson, R.M. and Clark, K.B. (1990) 'Architectural innovation: the reconfiguration of existing product technologies and the failure of established firms', Administrative Science Quarterly, Vol. 35, No. 1, pp.9-30.

Hill, C.W. (1988) 'Differentiation vs. low cost or differentiation and low cost', Academy of Management Review, Vol. 13, No. 3, pp.401-412.

Housein, G., Lin, B. and Wiesinger, G. (2002) 'Der Mitarbeiter im Fokus des Produktionsanlaufes. Management von Wissen, Qualifikation und Beziehungen als Garant für einen schnellen Produktionsanlauf', Wt Werkstattstechnik Online, Vol. 92, No. 10, pp.509-513.

Kotha, S. (1995) 'Mass customization: implementing the emerging paradigm for competitive advantage', Strategic Management Journal, Vol. 16, No. 5, pp.21-42.

Kuhn, A., Wiendahl, H-P., Eversheim, W. and Schuh, G. (2002) Schneller Produktionsanlauf von Serienprodukten. Ergebnisbericht der Untersuchung fast ramp-up, Dortmund.

Milgrom, P. and Roberts, J. (1990) 'The economics of modern manufacturing: technology, strategy, and organization', The American Economic Review, Vol. 80, No. 2, pp.511-528.

Miller, A. and Dess, G.G. (1993) 'Assessing Porter's model in terms of its generalizability, accuracy and simplicity', Journal of Management Studies, Vol. 30, No. 4, pp.553-585.

Ogawa, S. and Piller, F.T. (2006) 'Reducing the risk of new product development', MIT Sloan Management Review, Vol. 47, No. 2, pp.65-71.

Pelousek, W.F. and Bauer, D. (2005) 'Der Serienanlauf und seine Auswirkungen auf die Produktrendite', ZfAW - Zeitschrift für die gesamte Wertschöpfungskette Automobilwirtschaft, Vol. 8, No. 4, pp.22-26.

Piller, F.T. (1998) 'Kundenindividuelle Massenproduktion', WISU - Das Wirtschaftsstudium, Vol. 27, Nos. 8/9, pp.875-879.

Piller, F.T. (2001) Mass Customization - Ein wettbewerbsstrategisches Konzept im Informationszeitalter, 2nd ed., Gabler Verlag, Wiesbaden.

Piller, F.T. (2005) 'Mass customization: reflections on the state of the concept', International Journal of Flexible Manufacturing Systems, Vol. 16, No. 4, pp.313-334.

Piller, F.T. and Ihl, Ch. (2002) 'Mass Customization ohne Mythos', New Management, No. 10, pp.17-30.

Piller, F.T. and Moeslein, K. (2002) From Economies of Scale Towards Economies of Customer Integration: Value Creation in Mass Customization Based Electronic Commerce, Working Paper No. 31, Dept. of General and Industrial Management, Technische Universität München. 
Piller, F.T. and Stotko, C.M. (2002) 'Mass customization: four approaches to deliver customisation products and services with mass production efficiency', in Durrani, T.S. (Ed.): Managing Technology for the New Economy, Proceedings of the IEEE International Engineering Management Conference IEMC-2002, St. John's College, Cambridge, UK, 18-20 August 2002, Vol. II, pp.773-778.

Pine, B.J., II (1999) Mass Customization: The New Frontier in Business Competition, Harvard Business School Press, Boston, Massachusetts.

Pleschak, F. and Sabisch, H. (1996) Innovationsmanagement, UTB, Stuttgart.

Porter, M.E. (1980) Competitive Strategy, Techniques for Analyzing Industries and Competitors, The Free Press, New York.

Proff, H. and Proff, H.V. (1997) 'Möglichkeiten und Grenzen hybrider Strategien. Dargestellt am Beispiel der deutschen Automobilindustrie', Die Betriebswirtschaft, Vol. 57, No. 3, pp.797-809.

Proff, H. and Proff, H.V. (2008) Dynamisches Automobilmanagement: Strategien für international tätige Automobilhersteller und Zulieferer, Gabler Verlag, Wiesbaden.

Qiao, G., Lu, R.F. and McLean, C. (2006) 'Flexible manufacturing systems for mass customisation manufacturing', International Journal of Mass Customisation, Vol. 1, Nos. 2/3, pp.374-393.

Schuh, G., Kampker, B. and Franzkoch, B. (2005) 'Anlaufmanagement. Kosten senken Anlaufzeit verkürzen - qualität sichern', Wt Werkstattstechnik Online, Vol. 95, No. 5, pp.405-409.

Terwiesch, C. and $\mathrm{Xu}, \mathrm{Y}$. (2004) 'The copy exactly ramp-up strategy: trading-off learning with process change', IEEE Transactions on Engineering Management, Vol. 51, No. 1, pp.70-84.

Terwiesch, C., Bohn, R.E. and Chea, K.S. (2001) 'International product transfer and production ramp-up: a case study from the data storage industry', R\&D Management, Vol. 31, No. 4, pp.435-451.

Thompson, V.A. (1965) 'Bureaucracy and innovation', Administrative Science Quarterly, Special Issue on Professionals in Organizations, Vol. 10, No. 1, pp.1-20.

Ulrich, K. (1995) 'The role of product architecture in the manufacturing firm', Research Policy, Vol. 24, No. 3, pp.419-440.

Ulrich, K. and Probst, G.J.B. (1995) Anleitung zum ganzheitlichen Denken und Handeln. Ein Brevier für Führungskräfte, 4th ed., Haupt Verlag, Bern et al.

Utterback, J.M. (2003) 'The dynamics of innovation', The Internet and the University, Aspen Institute Forum 2002, Educause, pp.81-103.

Wiendahl, H-P., Hegenscheidt, M. and Winkler, H. (2002) 'Anlaufrobuste Produktionssysteme', Wt Werkstattstechnik Online, Vol. 92, Nos. 11/12, pp.650-655.

Wiesinger, G. and Housein, G. (2002) 'Schneller Produktionsanlauf von Serienprodukten. Wettbewerbsvorteile durch ein anforderungsgerechtes Anlaufmanagement', Wt Werkstattstechnik Online, Vol. 92, No. 10, pp.505-508.

Wildemann, H. (2004) 'Präventive Handlungsstrategien für den Produktionsanlauf', Industrie Management, Vol. 20, No. 4, pp.17-20.

Winkler, H. (2006) 'Entwicklung von Supply Chain Strategien für eine Virtuelle Supply Chain Organisation (VISCO)', Zeitschrift für Planung und Unternehmenssteuerung, Vol. 17, No. 1, pp.47-72.

Winkler, H. and Slamanig, M. (2008) 'Konzeption eines aktivitätsorientierten Instruments zur Anlaufkostenplanung', Zeitschrift für Planung und Unternehmenssteuerung, Vol. 19, No. 1, pp.85-106. 
Winkler, H., Slamanig, M. and Kaluza, B. (2007a) 'Ramp-up strategies for the product change in mass customization', in Blecker, Th., Edwards, K., Friedrich, G., Hvam, L. and Salvador, F. (Eds.): Innovative Processes and Products for Mass Customization, Gito Verlag, Berlin, pp.409-426.

Winkler, H., Slamanig, M. and Kaluza, B. (2007b) 'Functional requirements and design steps for a key metric system to plan ramp-up costs', in Molina, A., Erbe, H.H., Morales-Menéndez, R. and Cadena, M.R. (Eds.): Proceedings of IFAC-CEA Conference on Cost Effective Automation in Networked Product Development and Manufacturing, 2-5 October 2007, Monterrey, Mexico, pp.1-5.

Zaltman, G., Duncan, R. and Holbek, J. (1984) Innovations and Organizations, Wiley \& Sons, New York. 